\title{
Identifying Unique Protein Alterations Caused by SPTLC1 Mutations in a Transfected Neuronal Cell Model
}

\author{
Scott E. Stimpson ${ }^{1,2,3^{*}}$, Anu Shanu ${ }^{1,2,4^{*}}$, Jens R. Coorssen ${ }^{2,3,4,5 \#, ~ S i m o n ~ J . ~ M y e r s ~}{ }^{1,2,3,4 \#}$ \\ ${ }^{1}$ Neuro-Cell Biology Laboratory, Western Sydney University, Penrith, Australia \\ ${ }^{2}$ Molecular Medicine Research Group, Western Sydney University, Penrith, Australia \\ ${ }^{3}$ School of Science and Health, Western Sydney University, Penrith, Australia \\ ${ }^{4}$ School of Medicine, Western Sydney University, Penrith, Australia \\ ${ }^{5}$ Molecular Physiology, Western Sydney University, Penrith, Australia \\ Email:\#s.myers@uws.edu.au,\#jcoorssen@brocku.ca
}

How to cite this paper: Stimpson, S.E., Shanu, A., Coorssen, J.R. and Myers, S.J. (2016) Identifying Unique Protein Alterations Caused by SPTLC1 Mutations in a Transfected Neuronal Cell Model. Worla Journal of Neuroscience, 6, 325-347. http://dx.doi.org/10.4236/wins.2016.64035

Received: August 17, 2016

Accepted: November 27, 2016

Published: November 30, 2016

Copyright $\odot 2016$ by authors and Scientific Research Publishing Inc. This work is licensed under the Creative Commons Attribution International License (CC BY 4.0). http://creativecommons.org/licenses/by/4.0/

\begin{abstract}
Hereditary sensory neuropathy type I is an autosomal dominant disorder that affects the sensory neurons. Three missense mutations in serine palmitoyltransferase long chain subunit 1 cause hereditary sensory neuropathy type I. The endoplasmic reticulum, where the serine palmitoyltransferase long chain subunit 1 protein resides, and mitochondria are both altered in hereditary sensory neuropathy type I mutant cells. Employing a transfected neuronal cell line (ND15), we have identified and confirmed altered protein expression levels of ubiquinol cytochrome C, Hypoxia Up regulated Protein 1, Chloride Intracellular Channel Protein 1, Ubiqutin-40s Ribosomal Protein S27a, and Coactosin. Additionally, further 14 new proteins that exhibited altered expression within V144D, C133W and C133Y mutants were identified. These data have shown that mutations in SPTLC1 alter the expression of a set of proteins that may help to establish a causal link between the mitochondria and ER and the "dying back" process of dorsal root ganglion neurons that occurs in HSN-I.
\end{abstract}

\section{Keywords}

Hereditary Sensory Neuropathy Type 1, ND15, SPTLC1, ER Stress, Coactosin

\section{Introduction}

Hereditary Sensory Neuropathy type I (HSN-I) is an autosomal dominant inherited neurodegenerative disorder. It is caused by missense mutations in the open reading ${ }^{*}$ Both authors contributed equally 
frame of serine palmitoyltransferase (SPT) long chain subunit 1 (SPTLC1) [1], causing amino acid substitutions from cysteine to tryptophan at position $133(\mathrm{C} 133 \mathrm{~W})$, cysteine to tyrosine at position 133 (C133Y) or valine to aspartate at position 144 (V144D) [1]. SPT is an Endoplasmic Reticulum (ER) bound and a key rate-determining enzyme in the complex sphingolipid metabolic pathway [2]. HSN-I is characterised by degeneration in the Dorsal Root Ganglion (DRG) and presents with clinical onset between the second or third decades of life [2] [3] [4] [5].

In previous studies, we investigated altered protein profile changes in the mitochondria and ER of HSN-I patient cells (SPTLC1 V144D mutation) [6] [7] [8]. Changes in protein expression were identified in both the isolated mitochondria and ER subcellular fractions. Ubiquinol cytochrome $\mathrm{C}$ was most notably altered in expression within the mitochondria of the HSN-I patient cells. Within the ER fractions, Hypoxia up regulated Protein 1 (ORP-150), Chloride Intracellular Channel Protein 1 (CLIC1), Ubiqutin-40s Ribosomal Protein S27a (RPS27a), and Coactosin (COTL1) protein expression were increased in the HSN-I patient cells (SPTLC1 V144D mutation). In addition to these findings, further 36 proteins were identified from both the mitochondria and ER of HSN-I patients' cells by using top-down proteomic analyses [6] [7] [8]. Of these 36 proteins, the observed alterations were in proteins related to oxidative stress and cytoskeleton.

Based on these earlier findings, this investigation employed ND15 cell line (hybrid of rat dorsal root ganglion neuron and a mouse neuroblastoma) which had been transiently transfected (TT) to overexpress the three SPTLC1 missense mutations: V144D, C133W and C133Y. The data obtained from this ND15 neuronal cell model confirmed previous results from the HSN-I patient lymphoblast, while notably identifying changes exhibited in the C133W and C133Y mutations. We have also identified an additional 14 proteins that are altered in abundance within the transfected ND15 cells. Together these findings offer a greater insight into the molecular mechanisms occurring in the three known mutations causing HSN-I.

\section{Materials and Methods}

\subsection{ND15 Cell Culture}

All cell culture stock solutions, including DMEM, Foetal Bovine Serum (FBS), Penicillin $(100 \mathrm{U} / \mathrm{mL})$, Streptomycin $(100 \mu \mathrm{g} / \mathrm{mL})$, L-glutamine $(2 \mathrm{M})$, NEAA $(1 \mathrm{M})$, and phosphate buffered saline (PBS) were purchased from GIBCO Invitrogen (Australia). Cell culture consumables were purchased from BD Falcon (Greiner, USA). ORP-150, CLIC1, RPS27a, Calnexin, ubiquinol cytochrome C, MTCO2, and GAPDH primary antibodies were purchased from Abcam (USA); SPTLC1 primary antibody was purchased from Santa Cruz Biotechnology (USA). COTL1 primary antibody was purchased from Protein SciTech (USA). Kif2A and GFP primary antibodies were purchased from Merck Millipore (USA). Secondary horse radish peroxidase (HRP) mouse antibodies and DAPI stains were purchased from Sigma-Aldrich (Australia). ND15 cell lines were cultured in DMEM media, supplemented with FBS (10\% v/v), Penicillin (1 U/mL), 
Streptomycin $(1 \mu \mathrm{g} / \mathrm{mL})$, L-glutamine $(2 \mathrm{mM})$, and NEAA $(1 \mathrm{mM})$ at $37^{\circ} \mathrm{C}$ in a humidified atmosphere of $5 \% \mathrm{CO}_{2}$, in $\mathrm{T} 75 \mathrm{~cm}^{2}$ culture flasks (Greiner, Interpath). Prior to use in biochemical assays, ND15s were collected by centrifugation at $1500 \times g(5 \mathrm{~min}$ at RT) and washed in PBS. Cell counts were obtained using the Countess Automated Cell Counter (Invitrogen, Australia).

\subsection{Transient Transfections}

ND15 cells were transiently transfected (TT) with plasmid constructs (GFP-tagged SPTLC Wild type, V144D, C133W and C133Y mutants) using Lipofectamine 2000 (L2K; Invitrogen, USA). Cells were plated at a density of $2 \times 10^{5}$ per well in 6 well plates. Transfections were carried out when cells were 90\% - 95\% confluent (approximately 24 hours after plating, at $37^{\circ} \mathrm{C}$ and $5 \%\left(\mathrm{CO}_{2}\right.$ ), according to manufacturer instructions. Briefly, plasmid constructs and L2K reagent were diluted in $250 \mu \mathrm{L}$ of Opti-MEM I Reduced Serum Media (Invitrogen, USA), to yield $16 \mu \mathrm{g} / \mathrm{ml}$ DNA and 40 $\mu \mathrm{L} / \mathrm{ml} \mathrm{L} 2 \mathrm{~K}$. Within 5 min of each dilution, the DNA construct diluents and L2K diluents were combined and incubated for $30 \mathrm{~min}$ at $25^{\circ} \mathrm{C}$. After incubation, DNA-L2K complexes $(500 \mu \mathrm{L})$ were added into each well, as required. The cells were then incubated at $37^{\circ} \mathrm{C}$ in a humidified atmosphere of $5 \% \mathrm{CO}_{2}$ for $6 \mathrm{~h}$. Cells then had media replaced with fresh media and were left to incubate for $48 \mathrm{~h}$. Post transfection, cells were harvested and cell lysate was used for further analyses.

\subsection{Detection of Total Protein Concentration}

Determination of total cellular protein was carried out using the EZQ Protein Estimation Assay (Invitrogen, Australia) as previously described [9].

\subsection{SDS-PAGE and Immunoblotting}

Nontransfected, wild type and mutant protein fractions ( $25 \mu \mathrm{g}$ total protein) were subjected to SDS-PAGE on $12.5 \%$ resolving gels and transferred to PVDF membrane. The membranes were blocked with 5\% skim milk in TBS buffer containing $0.1 \%$ Tween-20. Whole membranes were blocked and incubated with anti-SPTLC1, anti-GAPDH, antiORP-150, anti-CLIC1, anti-RPS27a, anti-COTL1, anti-MTCO2, anti-GFP and antiKif2A antibodies respectively, at 1:1000 dilution, for $16 \mathrm{~h}$. Membranes were washed and incubated with secondary HRP antibody (1:2000 dilution) for $1 \mathrm{~h}$ at RT. Blots were washed and developed using an enhanced chemiluminescence (ECL) detection kit (Pierce Thermo Scientific, USA). Membranes were developed on CL-Xposure Film (Thermo Fisher Scientific, USA) using an AGFA X-ray developer.

\subsection{Immunofluorescence}

Immunofluorescence was carried out as previously described [6]. Briefly, ND15 cells $(1 \times$ $10^{6}$ cells) were grown on glass coverslips in 6-well plates $24 \mathrm{~h}$ prior to transfection. $48 \mathrm{~h}$ post transfection, cells were washed and $4 \%$ paraformaldehyde was added for $15 \mathrm{~min}$. Following incubation, cells were washed and placed in $0.5 \%$ TritoX-100 and incubated 
at $37^{\circ} \mathrm{C}$ for $20 \mathrm{~min}$. The cells were then blocked in $5 \% \mathrm{BSA}$ solution at $37^{\circ} \mathrm{C} \mathrm{C}$ for 30 min, then incubated in primary antibody against SPTLC1, Kif2A, Cytochrome C, RPS27a, CLIC1, ORP-150, COTL1, Calnexin and MTCO2, and incubated for $1 \mathrm{~h}$ at RT. The cells were subsequently washed and incubated in secondary antibody, anti-mouse Rhodamine (Millipore, 1:200), for $1 \mathrm{~h}$ at RT. Nuclei were stained with DAPI $(1 \mu \mathrm{g} / \mu \mathrm{L})$ for $2 \mathrm{~min}$, after which the cells were washed and dried overnight. The coverslips were then mounted onto glass slides prior to confocal imaging using the LSM 5 confocal microscope comprising the LSM 5 exciter laser scanning microscope with Axiovert $200 \mathrm{M}$ inverted optical microscope (Carl Zeiss, Jena, Germany).

\subsection{Flow Cytometry}

FACS analyses were carried out as previously described [6]. ND15 cells were transfected as above, and cells were then suspended in $4 \%$ paraformaldehyde and incubated for $15 \mathrm{~min}$ at $\mathrm{RT}$ and then resuspended in $0.3 \%$ Triton X-100 for $15 \mathrm{~min}$ at $37^{\circ} \mathrm{C}$. After incubation the cell suspension was centrifuged at $1000 \times g$ for $5 \mathrm{~min}$ and the pellet resuspended in primary antibody for $1 \mathrm{~h}$ at RT. Cell suspension was centrifuged, washed in PBS and resuspended in secondary antibody, anti-mouse or anti-rabbit Rhodamine (Millipore, 1:200) for $1 \mathrm{~h}$ at RT. The cell suspension was then analysed using the MACSQuant flow cytometer (Miltenyi Biotech, Germany).

\subsection{Two Dimensional Gel Electrophoresis}

2DE was carried out as previously described [6] [10] [11] [12] using a total of $100 \mu \mathrm{g}$ protein for each analysis. Briefly, whole ND15 proteins were reduced and alkylated in solutions containing total protein extraction buffer (containing $8 \mathrm{M}$ urea, $2 \mathrm{M}$ thiourea and $4 \%$ CHAPS without ampholytes), total extraction buffer with $2 \%$ ampholytes, TBP/ DTT disulphide reduction buffer (2.3 $\mathrm{mM}$ Tributyl phosphine and $45 \mathrm{mM}$ DTT) and alkylation buffer (230 $\mathrm{mM}$ acrylamide monomer).

The treated samples were added to $7 \mathrm{~cm}$ Non-Linear pH 3 - 10 IPG strips (Bio-Rad ReadyStrip), and rehydrated for $16 \mathrm{~h}$ at RT. Isoelectric focusing (IEF) was then carried out at $20^{\circ} \mathrm{C}$ using the Protean IEF Cell (Bio-Rad, USA). After IEF, IPG strips were resolved in the second dimension using a $12.5 \% \mathrm{~T}, 2.6 \% \mathrm{C}$ polyacrylamide gel buffered with $375 \mathrm{mM}$ Tris buffer ( $\mathrm{pH} 8.8), 0.1 \%(\mathrm{w} / \mathrm{v})$ sodium dodecyl sulphate and polymerised with $0.05 \%(\mathrm{w} / \mathrm{v})$ ammonium persulphate and $0.05 \%(\mathrm{v} / \mathrm{v})$ tetramethylethylenediamine (TEMED). A stacking gel containing $5 \% \mathrm{~T}, 2.6 \% \mathrm{C}$ polyacrylamide buffered with $375 \mathrm{mM}$ Tris buffer ( $\mathrm{pH} 6.8$ ), 0.1\% (w/v) SDS and 0.1\% bromophenol blue was added to the resolving gel. The IPG strips were placed onto the stacking gel and overlaid with $0.5 \%(\mathrm{w} / \mathrm{v})$ low melting agarose dissolved in $375 \mathrm{mM}$ Tris ( $\mathrm{pH} 8.8$ ), with $0.1 \%$ $(\mathrm{w} / \mathrm{v}) \mathrm{SDS}$. Electrophoresis was carried out at $4^{\circ} \mathrm{C} ; 150 \mathrm{~V}$ initially for $10 \mathrm{~min}$ then reduced to $90 \mathrm{~V}$ for $2.5 \mathrm{~h}$.

Following electrophoresis, the gels were placed in fixative containing $10 \%$ methanol and $7 \%$ acetic acid for $1 \mathrm{~h}$. The gels were then washed with distilled water for $20 \mathrm{~min}, 3$ times and subsequently stained with colloidal coomassie blue (0.1\% (w/v) CCB G-250, 
$2 \%(\mathrm{v} / \mathrm{v})$ phosphoric acid, $10 \%(\mathrm{w} / \mathrm{v})$ ammonium sulphate and $20 \%(\mathrm{v} / \mathrm{v})$ methanol) for $20 \mathrm{~h}$, with constant shaking at RT [11]; the gels were then de-stained 5 times with $0.5 \mathrm{M}$ $\mathrm{NaCl}, 15$ min each. Imaging of CCB-stained gels on the FLA-9000 imager (FUJIFILM, Tokyo, Japan) was carried out at 685/750 excitation/emission with a photomultiplier tube (PMT) setting of $600 \mathrm{~V}$ and pixel resolution set to $100 \mu \mathrm{m}$ [11]. Analysis of 2D gel images was performed using Delta 2D software with automated spot detection (Local Background Region: 96; Average Spot Size: 32 and sensitivity in percentage: 20.0) (version 4.0.8; DECODON GmbH, Gerifswald, Germany).

\subsection{Mass Spectrometry}

The following selection criteria were applied for spot inclusion. Changes in mean normalised spot volume (the abundance of resolved protein species) had to be greater than a 1.0 fold difference between samples from wild type versus V144D, C133W and C133Y mutants and be present in all replicate gels [11] [12]. Briefly, the protein species of interest were excised from gels and de-stained overnight. The gel pieces were then reduced and alkylated in $10 \mathrm{mM}$ Dithiothreitol (DTT) and $15 \mathrm{mM}$ Idoacetic acid (IAA), and subsequently incubated with trypsin solution (10 ng/ $\mu \mathrm{L}, \mathrm{pH} 7.4)$ for 16 hours at $37^{\circ} \mathrm{C}$. LC-MS/MS analysis was carried out on a nano Aquity UPLC (Waters Corp., Milford, MA, USA) linked to a XevoQToF mass spectrometer from Waters (Micromass, UK). The data were acquired using Masslynx software (Version 4.1, Micromass UK). The MS/MS data files were searched against Swiss Prot databases with semi-trypsin as the enzyme.

\subsection{Calcium Imaging}

ND15 cells were grown for $24 \mathrm{~h}$ in $35 \mathrm{~mm}$ glass bottom size 0 dish (MatTek, USA), and transfected as previously described. Molecular Probes Rhod-3 calcium imaging kit (Molecular Probes, USA) was used to stain the cells. Briefly, cells were incubated at RT in the dark for $1 \mathrm{~h}$ in $10 \mu \mathrm{M}$ Rohd-3 AM, $2.5 \mathrm{mM}$ probenecid and $1 \times$ power load. Cells were briefly washed in calcium-free PBS and incubated for a further $1 \mathrm{~h}$ at RT with 2.5 $\mathrm{mM}$ probenecid. To obtain low and high intracellular calcium images, NT ND15 cells were infused with PBS without calcium, containing $5 \mathrm{mM}$ EGTA and $2 \mu \mathrm{M}$ ionomycin to allow intracellular calcium to efflux from the cell. High intracellular calcium images were obtained by infusing the cells in PBS containing calcium and $2 \mu \mathrm{M}$ ionomycin. Cells were ready for imaging after a further two washes in calcium-free PBS and imaged on the LSM 5 confocal microscope comprising the LSM 5 exciter laser scanning microscope with Axiovert 200M inverted optical microscope (Carl Zeiss, Jena, Germany).

\section{Results}

\subsection{Expression of Proteins Identified in HSN-1 Transfected ND15 Cells}

In order to assess the level of expression of proteins previously reported as altered, total cellular protein fractions from nontransfected, wild type and mutant HSN-I TT ND15 cells were isolated and quantitative immunoblot analyses were carried out (Figure 1). 


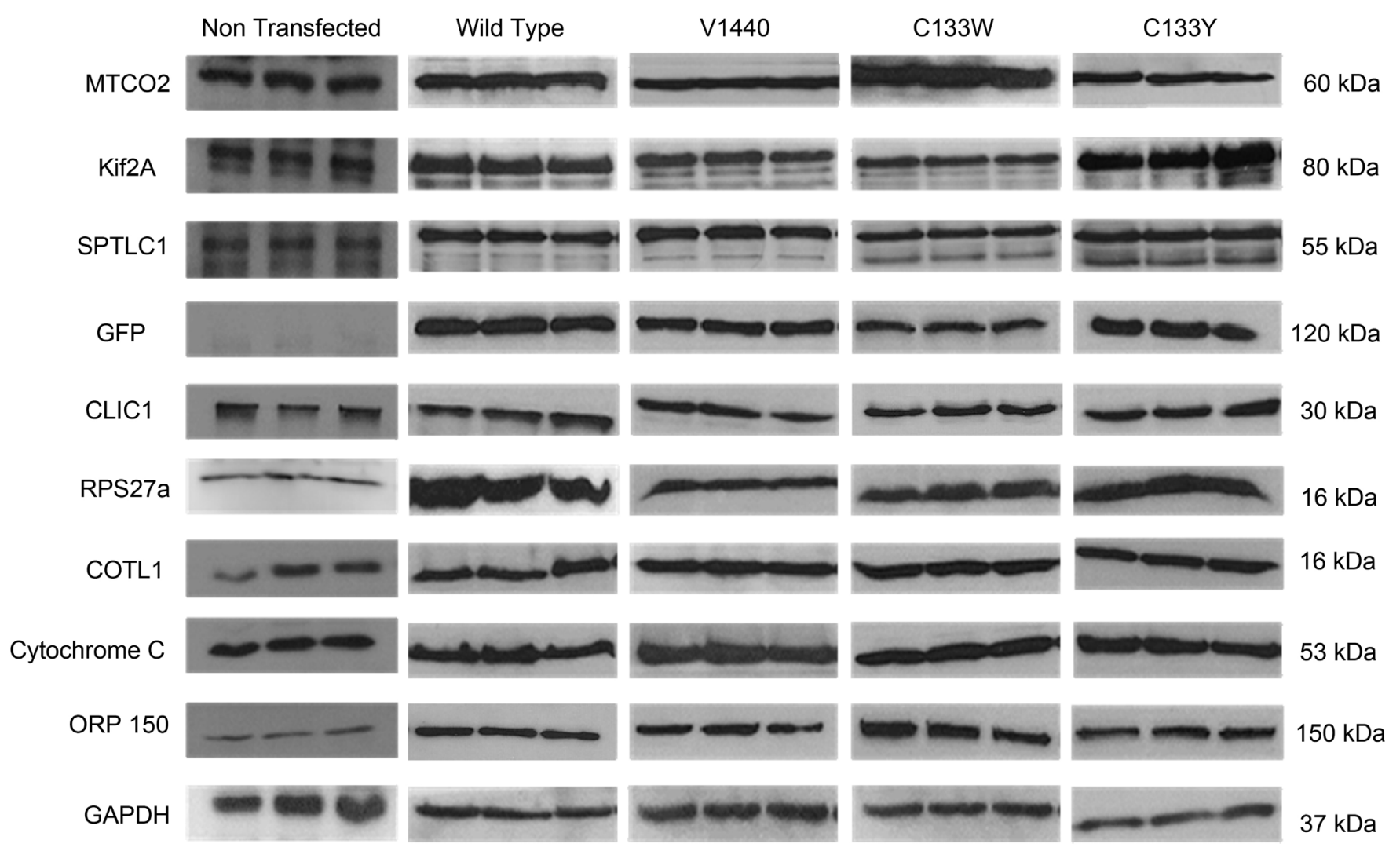

Figure 1. Immunoblots of proteins identified in nontransfected, wild type, V144D, C133W and C133Y transfected ND15 cells. $25 \mu \mathrm{g}$ of protein loaded per lane $(\mathrm{n}=3)$.

Quantitation of the immunoblot data (Figures 2(a)-(j)), confirmed that there were statistically significant $(p<0.05)$ changes in expression of COTL1 (Figure $2(\mathrm{~g}))$, Cytochrome C (Figure 2(h)) and ORP-150 (Figure 2(i)) in all mutants compared to the wild type, while RPS27a (Figure 2(f)) was significantly increased in V144D and C133Y. Although CLIC1 did not show any statistically significant increase in expression (Figure 2(e)), there was however an increase in expression in all mutants compared to the wild type. MTCO2 (Figure 2(a)), GFP (Figure 2(d)), SPTLC1 (Figure 2(c)), GAPDH (Figure 2(j)) and Kif2A (Figure 2(b)) showed no differential expression compared to the wild type.

\subsection{Intracellular Localisation Analyses of SPTLC1 and Proteins within Transiently Transfected ND15 Cells}

The intracellular localisation and abundance of the proteins SPTLC1, Kif2A, Cytochrome C, RPS27a, CLIC1, ORP-150, COTL1 and MTCO2 were established using immunostained nontransfected, wild type and mutant TT ND15 cells. There were no apparent changes in intracellular localisation of the SPTLC1 when transfected with GFP labelled SPTLC1, which was found localised to the perinuclear region where the ER resides (Figure 3(a)). Kif2A is a microtubule associated protein distributed evenly across the cytoskeleton [14]. Kif2A displayed consistent cytoskeletal pattern throughout the 

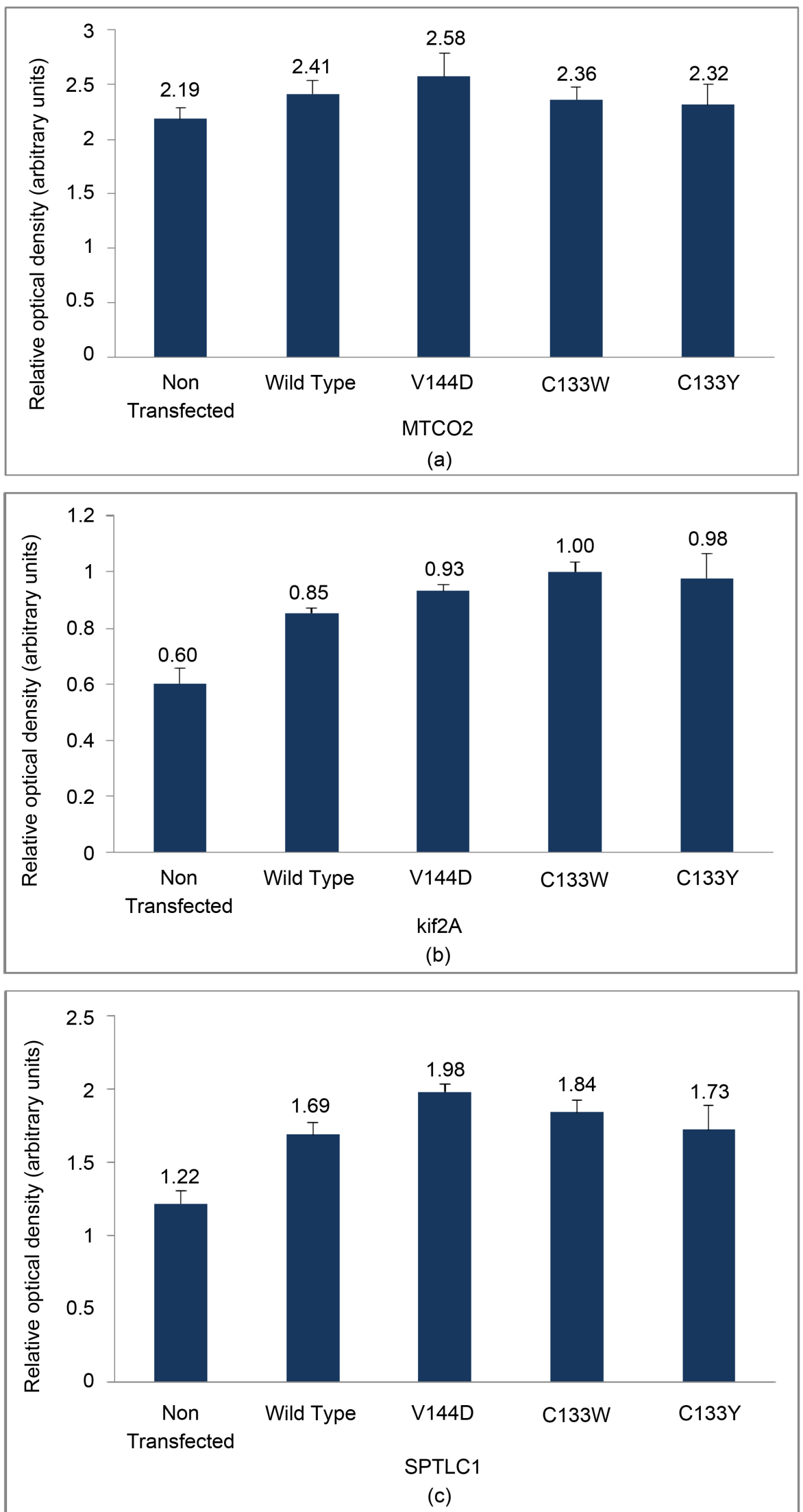

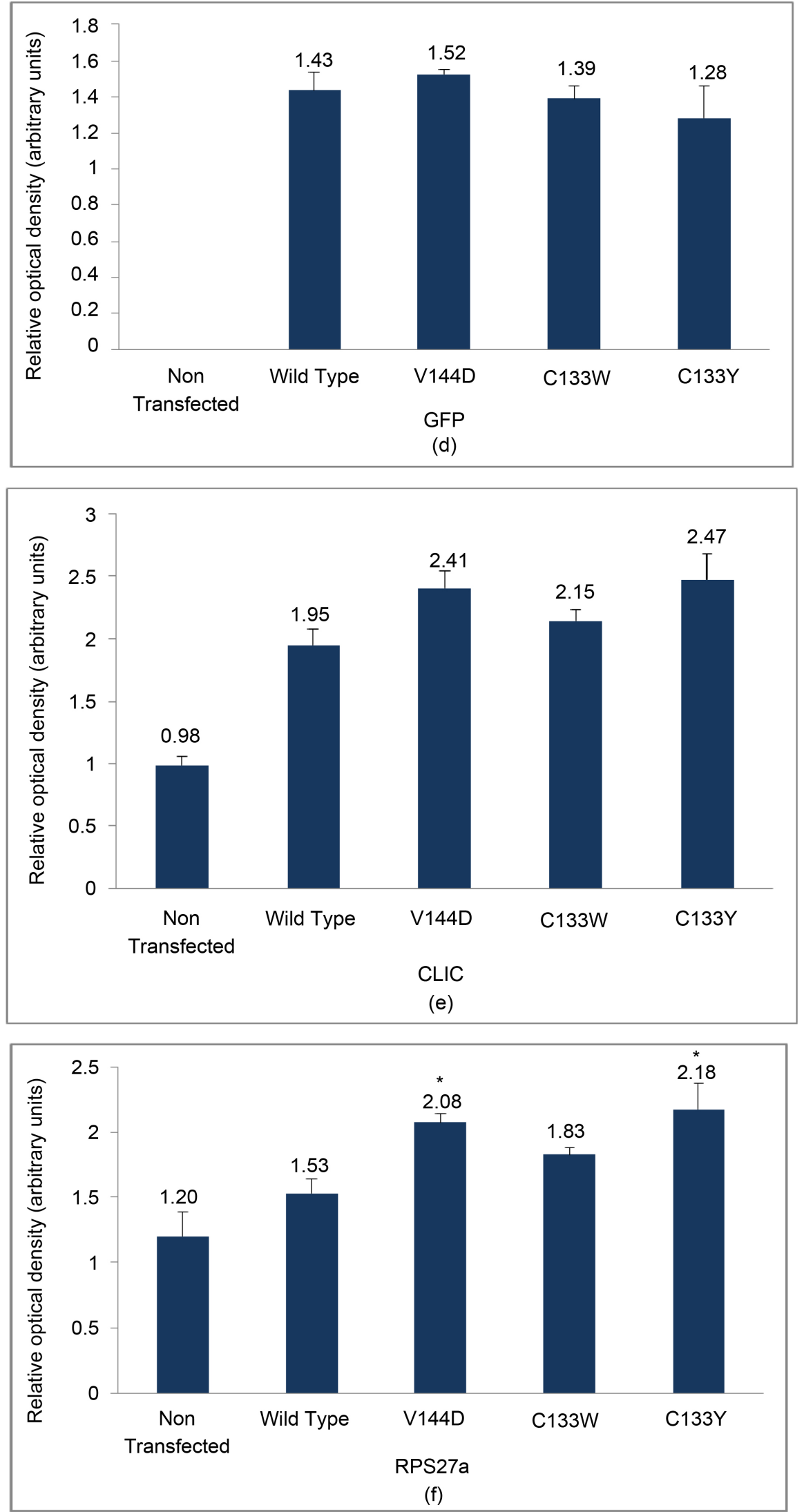

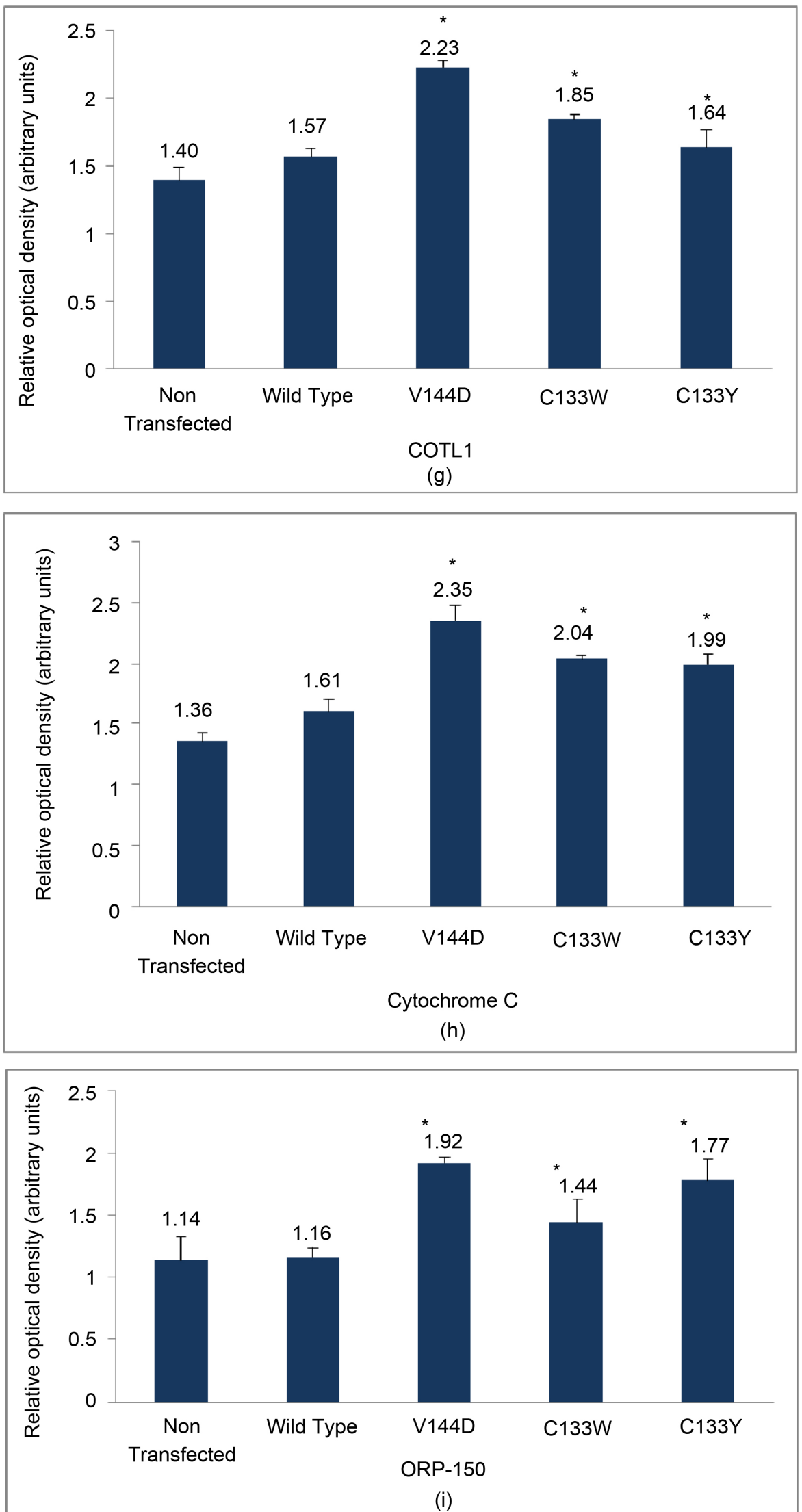


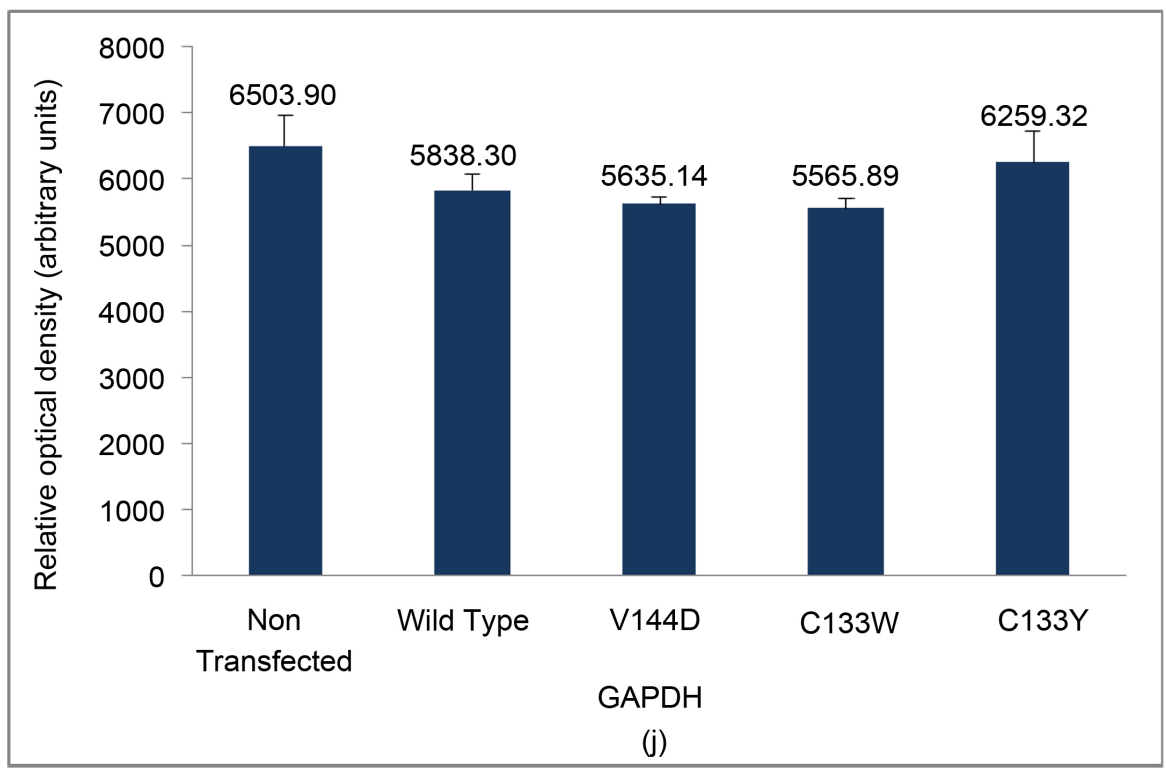

Figure 2. Expression of proteins in HSN-I transfected ND15 cells. Representative graphs showing the difference between nontransfected, wild type and mutant ND15 proteins. (a) MTCO2, (b) Kif2A, (c) SPTLC1, (d) GFP, (e) CLIC1, (f) RPS27a, (g) COTL1, (h) Cytochrome C, (i) ORP-150, and (j) GAPDH $\left(^{*}\right) \mathrm{p}<0.05$ statistically significant increase $(\mathrm{n}=$ 3). Errors bar depict SE of means. Blots were normalised to GAPDH.

cell in nontransfected, wild type and mutants (Figure 3(b)). MTCO2 is classically found to be distributed across the mitochondrial inner membrane. MTCO2 was distributed evenly throughout the mitochondria of the cells, indicating no change in the localisation within the mitochondria of mutant cells compared to the nontransfected and wild type cells (Figure $3(\mathrm{~h})$ ).

Cytochrome $\mathrm{C}$ is typically located within the mitochondrial inner membrane [15]. Interestingly, Cytochrome $\mathrm{C}$ showed a more perinuclear clustering in the mutant cells compared to that of the nontransfected and wild type cells, where the proteins were found to be more evenly distributed throughout the periphery of the cells (Figure 3(c)). RPS27a is located within the cytoplasm and nucleoplasm of cells [16]. With these proteins being evenly distributed throughout the cells in the nontransfected and wild type and mutants indicating no clustering of ubiquinated proteins (Figure 3(d)). CLIC1 exists in a soluble and membrane bound form, typically distributed evenly within the cells [17]. CLIC1 was localised in the cell periphery in the nontransfected, wild type and mutant cells (Figure 3(e)). However the mutants displayed a larger localisation towards the perinuclear region, indicating that CLIC1 may be present more in the membrane form in the mutants.

ORP-150, a chaperon protein localised throughout the cell [18], was found to be distributed throughout the wild type and mutant cells. ORP-150 was also found to be more abundant within the mutants compared to the nontransfected and wild type cells (Figure 3(f)). COTL1 is a cytoskeletal associated protein interacting with the cytoskeleton [19]. COTL1 exhibited an even cytoskeletal pattern through all the cells. Interes- 
(a) SPTLC1
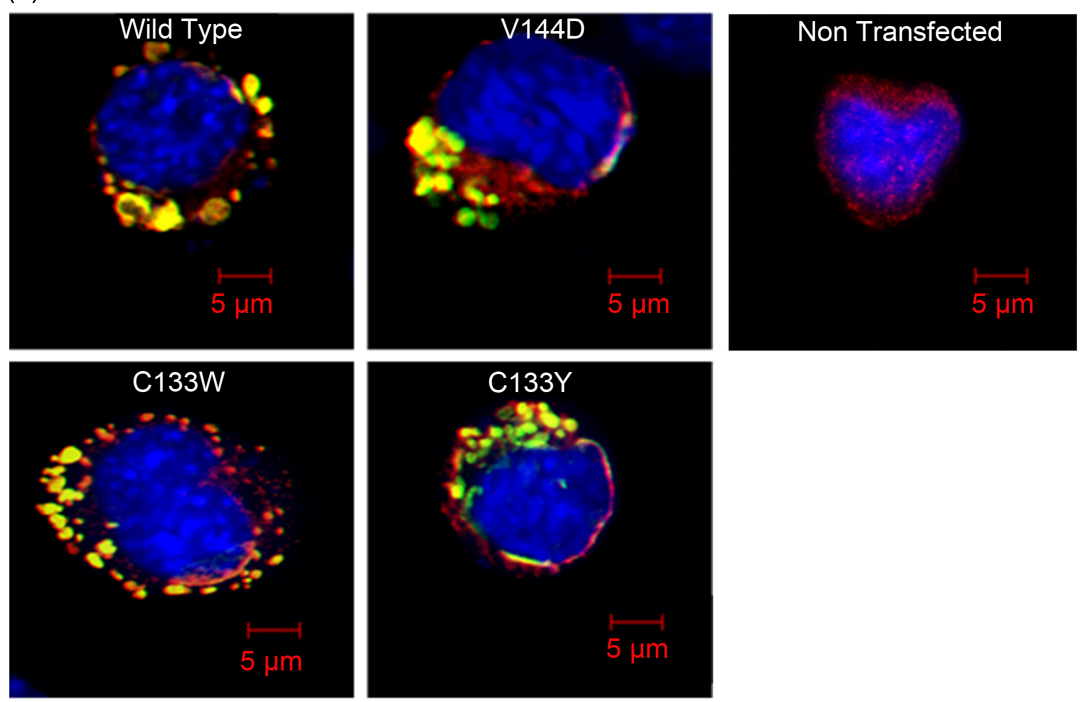

(b) Kif $2 \mathrm{~A}$
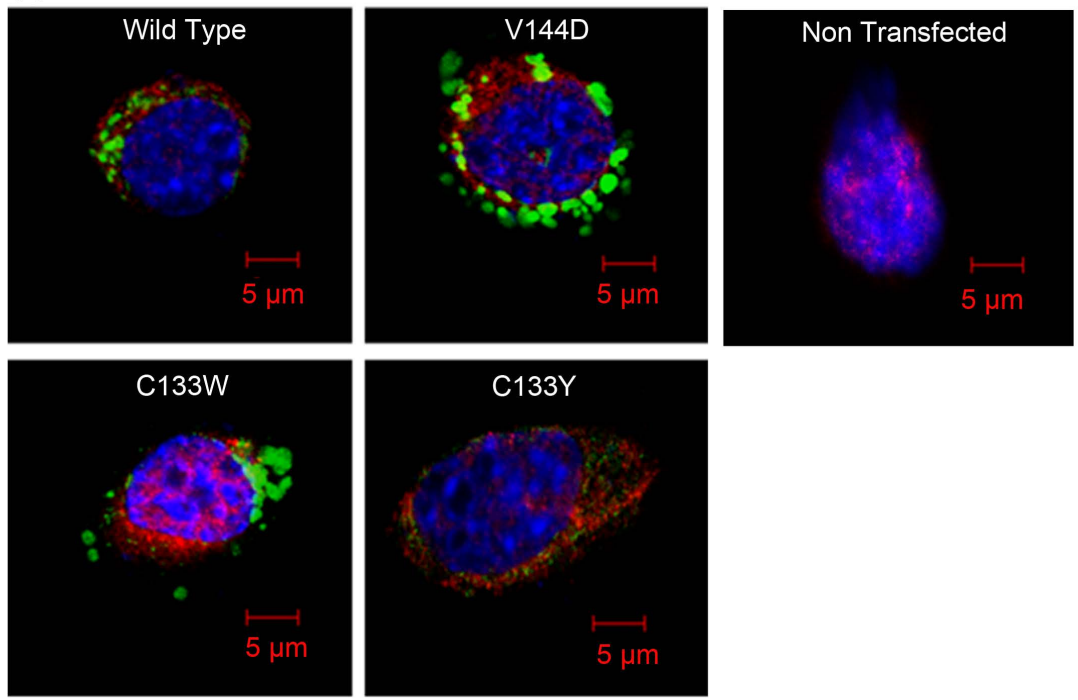

(c) Cytochrome C
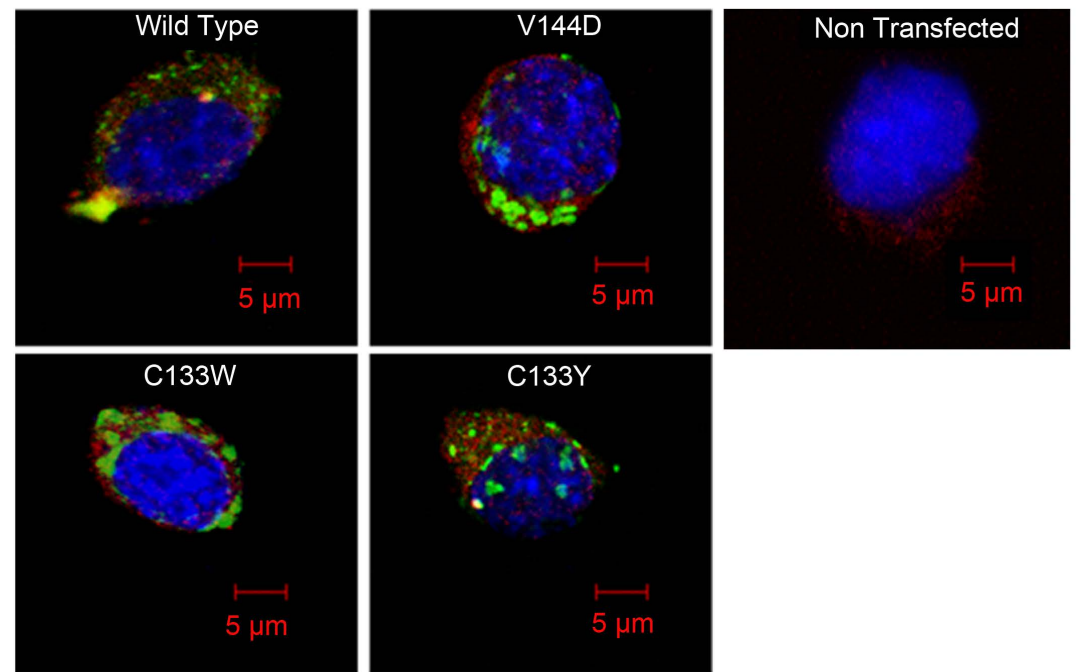
(d) RPS27a
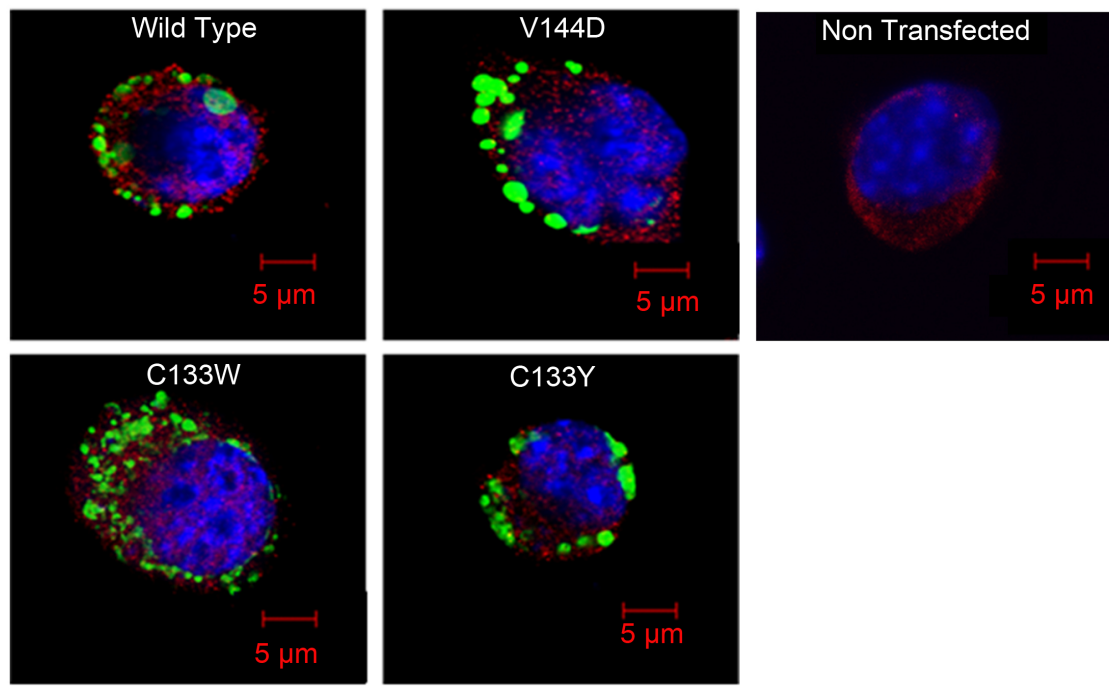

(e) CLIC 1
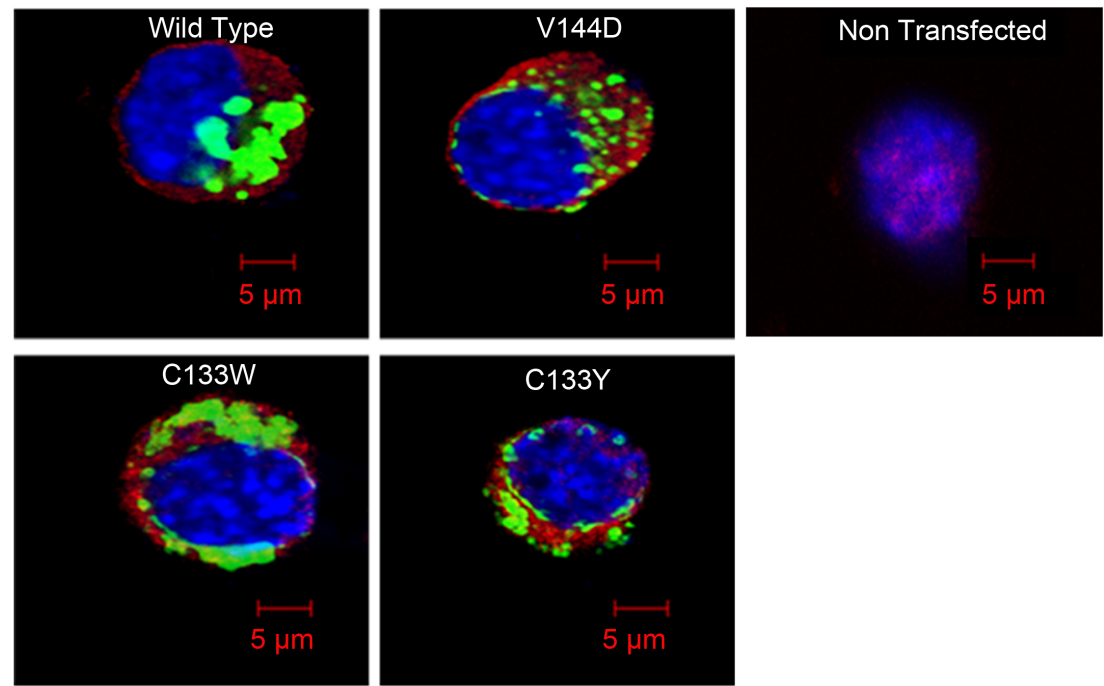

(f) ORP 150
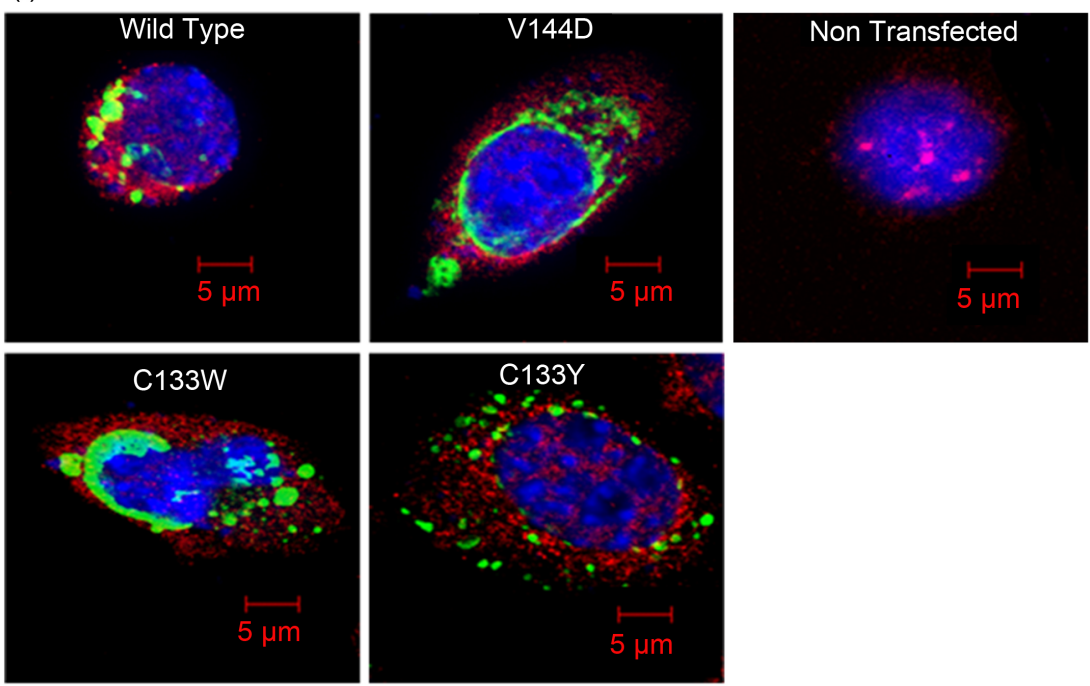
(g) COTL 1
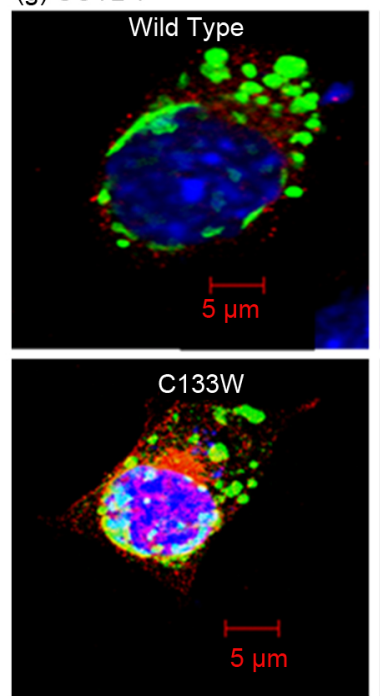

(h) MTCO2
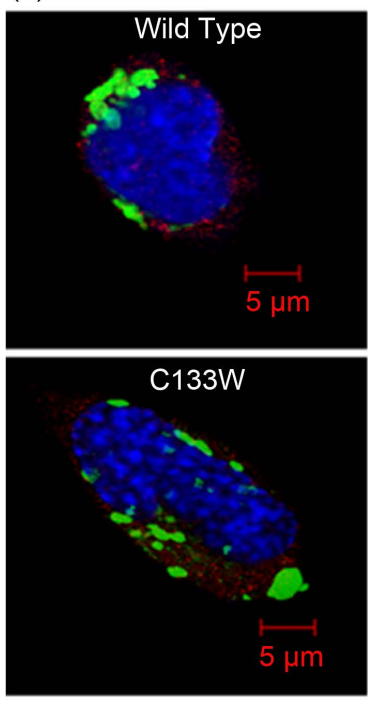
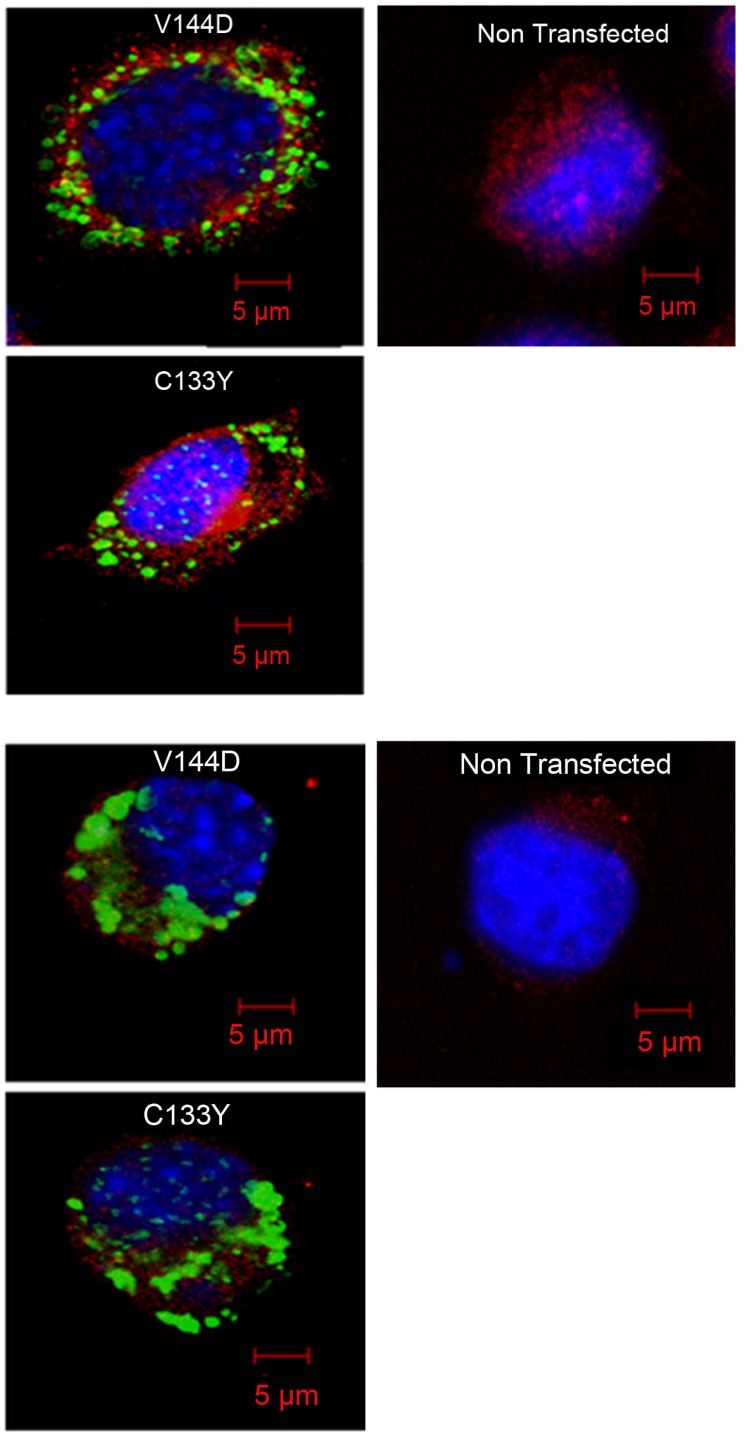

Figure 3. Representative immunofluorescence images of the intracellular localisation of proteins in transfected ND15 cells. Representative confocal micrographs showing (a) SPTLC1, (b) Kif2A, (c) Cytochrome C, (d) RPS27a, (e) CLIC1, (f) ORP-150, (g) COTL1 and (h) MTCO2 stained transfected (Green) ND15 cells (red) DAPI nuclear stain (blue). Scale bar $=5 \mu \mathrm{m}$.

tingly, there appeared to be a more perinuclear clustering (as indicated by arrows, Figure $3(\mathrm{~g})$ ) and potential co-localisation in the C133W and C133Y mutants in comparison to the nontransfected and wild type cells.

\subsection{FACS Analyses of Wild Type, V144D-, C133W- and C133Y-Transfected ND15 Cells Reveal Changes in Fluorescence Intensity of CLIC1, Cytochrome C, ORP-150 and RPS27a}

Fluorescence assisted cell sorting (FACS) was used to determine the total fluorescence per cell of TT ND15 immunostained cells for the proteins SPTLC1, Kif2A, Cytochrome 
C, RPS27a, CLIC1, ORP-150, COTL1, MTCO2 and GFP (Figure 4). There was a marked increase in the relative fluorescence intensity of CLIC1 (Figure 4(e)), Cytochrome C (Figure 4(c)), ORP-150 (Figure 4(f)) and RPS27a (Figure 4(d)) in the mutant
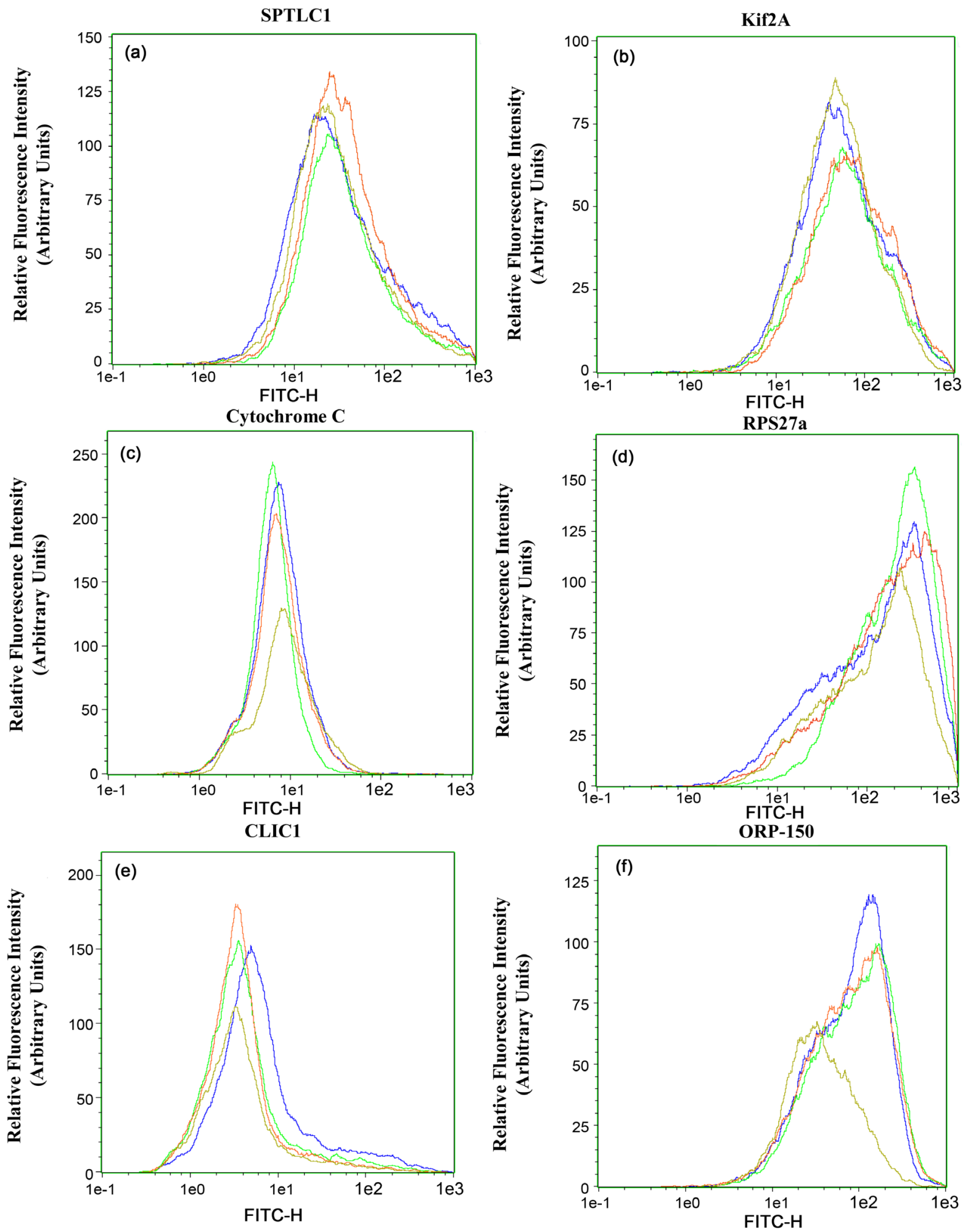


\section{COTL1}

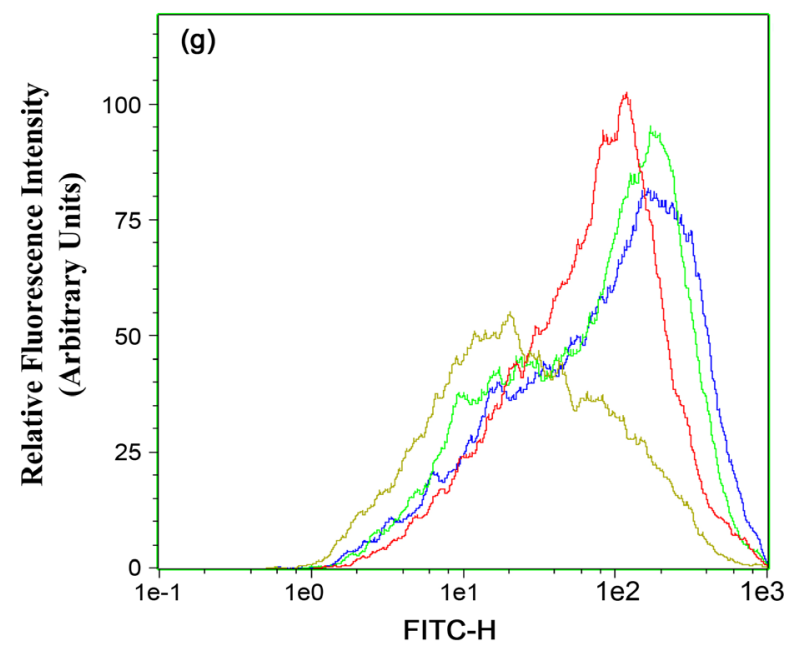

MTCO2

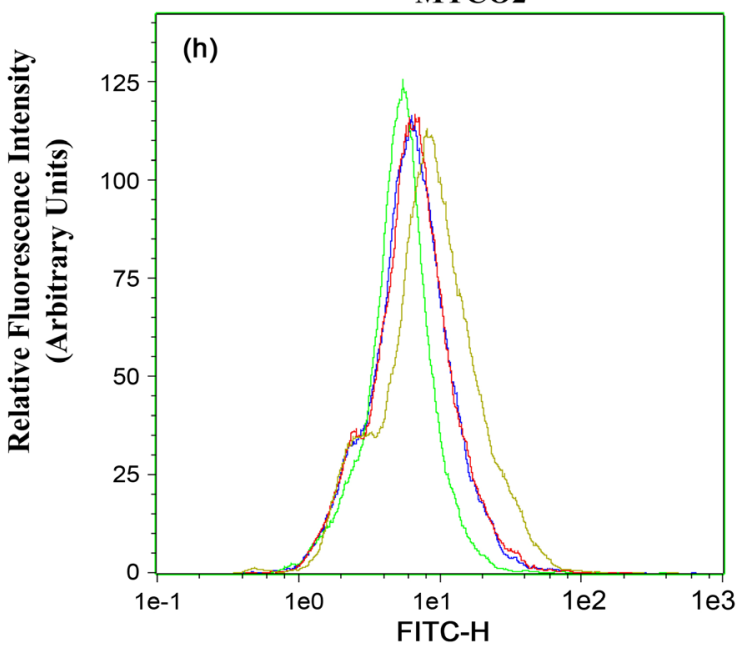

GFP

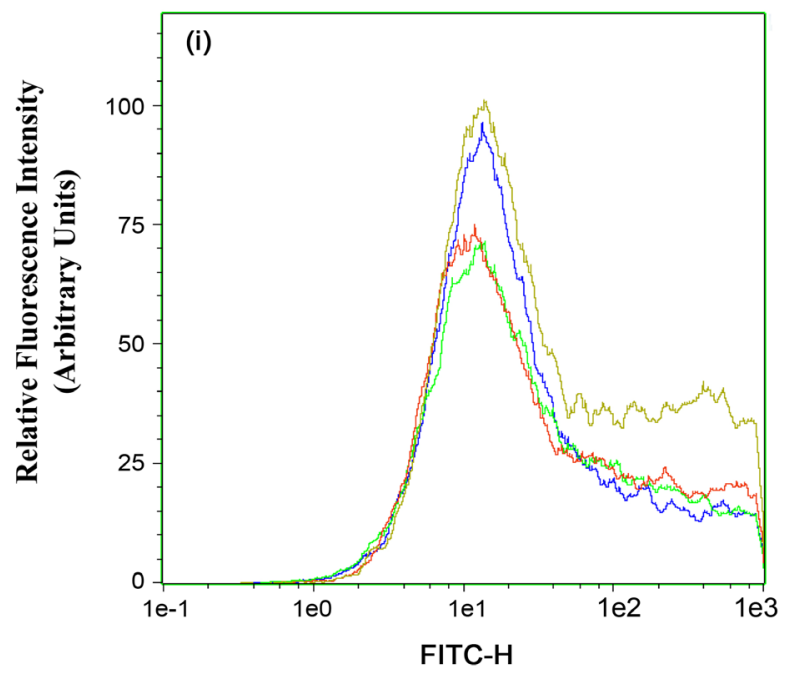

Figure 4. Relative quantification of Wild type, V144D, C133W and C133Y transfected ND15 cells. Flow cytometry analysis of the relative fluorescence intensity of (a) SPTLC1, (b) Kif2A (c) Cytochrome C (d) RPS27a (e) CLIC1 (f) ORP-150 (g) COTL1 (h) MTCO2 and (i) GFP. Gold histogram represents Wild Type, Blue histogram represents V144D, Green histogram represents $\mathrm{C} 133 \mathrm{~W}$ and Red histogram represents C133Y $(\mathrm{n}=3)$.

cells compared to that of wild type. There were no changes to SPTLC1 (Figure 4(a)), Kif2A (Figure 4(b)) and GFP (Figure 4(i)) in the wild type and mutants. These results correlate with the quantitative immunoblot data presented in Figure 2.

\subsection{Resolution of Total Cellular Proteins Using 2D Gels from SPTLC1-Transfected ND15 Cells}

Total isolated wild type and mutant ND15 proteins were resolved and quantitatively assessed using refined two dimensional gel electrophoresis (2DE) [10] [11]. The samples resolved covering the entire MW and PI range in triplicates (Figure 5). Standard spot counts indicated $674 \pm 7,669 \pm 4,663 \pm 9$ and $655 \pm 5$ protein species were resolved in wild type, V144D, C133W and C133Y mutant fractions respectively. LC/MS 
data coupled with Mascot Daemon searches of SwissProt database resulted in identification of a further 14 protein alterations in the three mutant samples relative to the wild type, as summarised in Table 1.

\subsection{Alterations within the Intracellular Calcium Levels of V144D-, C133W-, C133Y-Transfected ND15 Cells Compared to that of Wild Type and Nontransfected Controls}

Wild type and mutant ND15 cells were analysed for total intracellular calcium using the Rhod-3 Am calcium stain (Figure 6). Cell images were analysed using Image (NIH, USA) and corrected total cellular fluorescence was obtained. Analyses revealed a marked decrease in intracellular calcium in C133W and C133Y mutant cells. V144D mutant cells however, showed an increase in intracellular calcium when compared against basal levels determined in wild type and nontransfected (NT) cells (Figure 7).

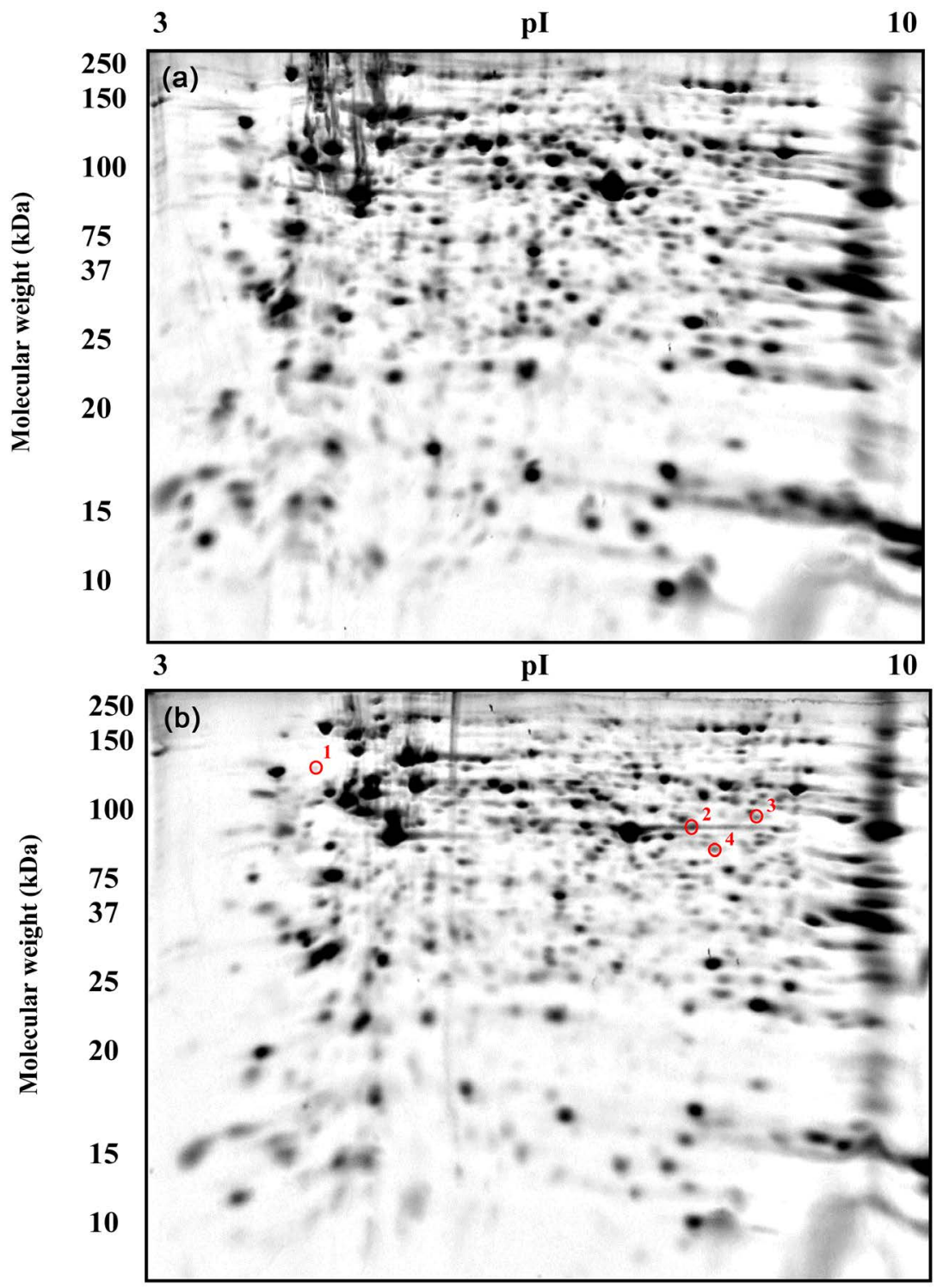



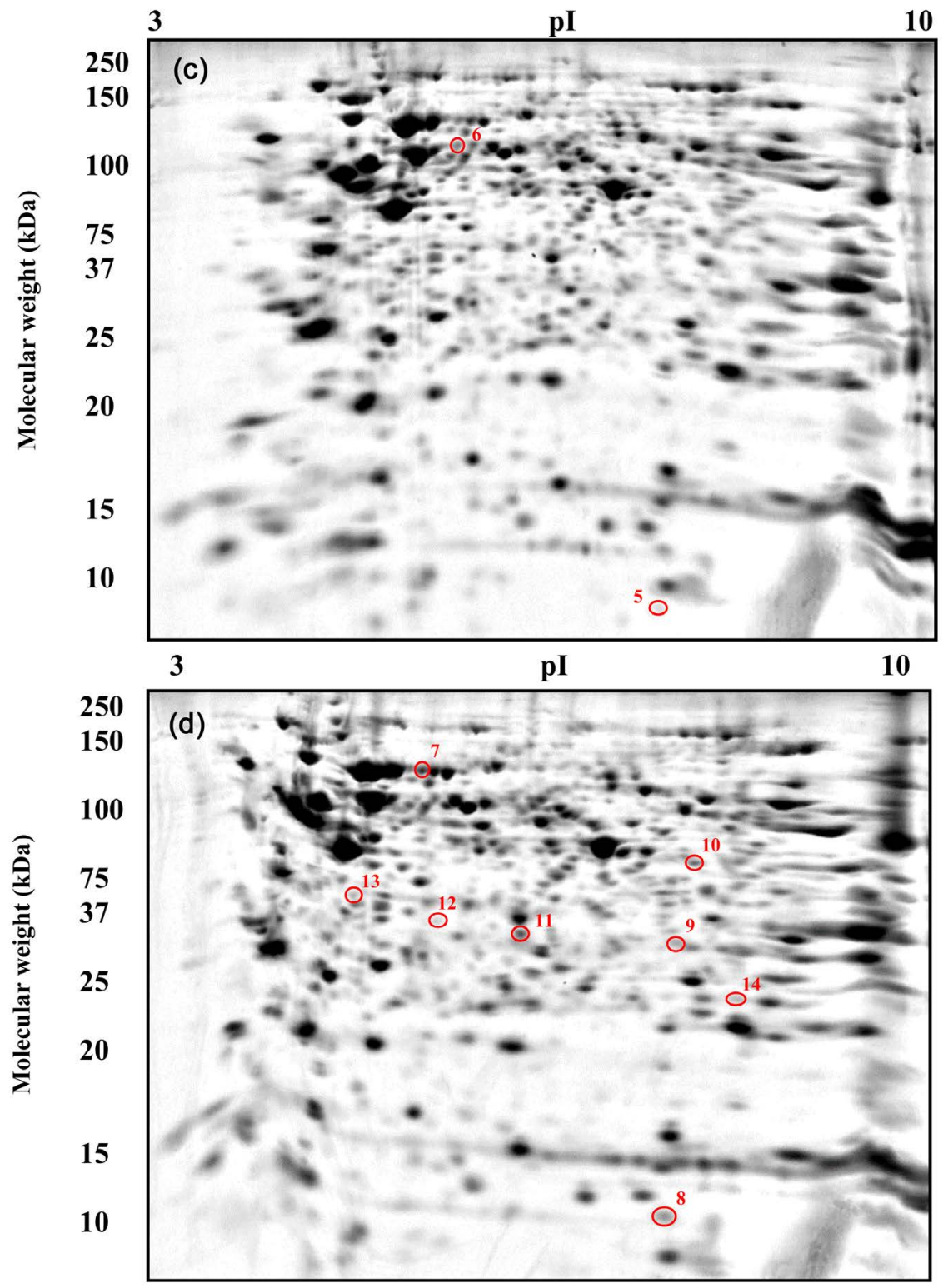

Figure 5. Representative images of 2D gels following resolution of total cellular proteins from HSN-1 transfected ND15 cells. (a) Wild type proteins (b) V144D proteins (c) $\mathrm{C} 133 \mathrm{~W}$ proteins and (d) $\mathrm{C} 133 \mathrm{Y}$ proteins. The molecular weights are in kilo Daltons $(\mathrm{kDa})$ and the IEF dimension is in $\mathrm{pH}$ units.

\section{Discussion}

Mutations in the SPTLC1 subunit are known to be causal in HSN-I. Molecular and cellular studies of cells over-expressing the SPTLC1 mutations have identified potential dysfunction in sphingolipid biosynthesis and metabolic activity [4]. This investigation correlates the previous findings from the lymphoblast cell model done in our group [6] [7] [8] [13] with a neuronal cell model. In addition to the V144D mutation, we have also investigated changes within the $\mathrm{C} 133 \mathrm{~W}$ and $\mathrm{C} 133 \mathrm{Y}$ mutations causing HSN-I.

Ubiquinol cytochrome $\mathrm{C}$ reductase core protein 1 is a central component of the 
(a)

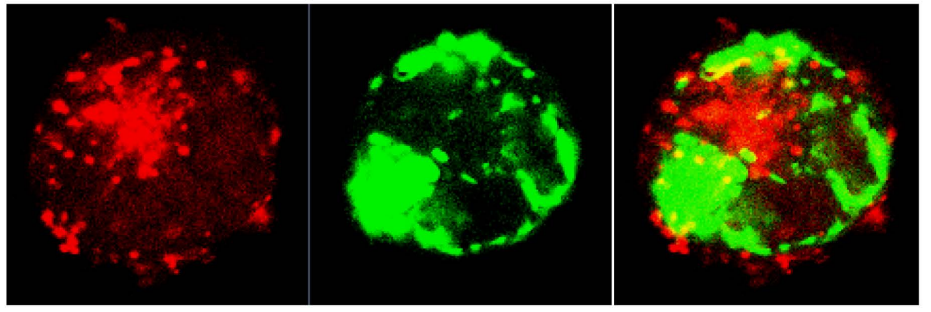

(b)

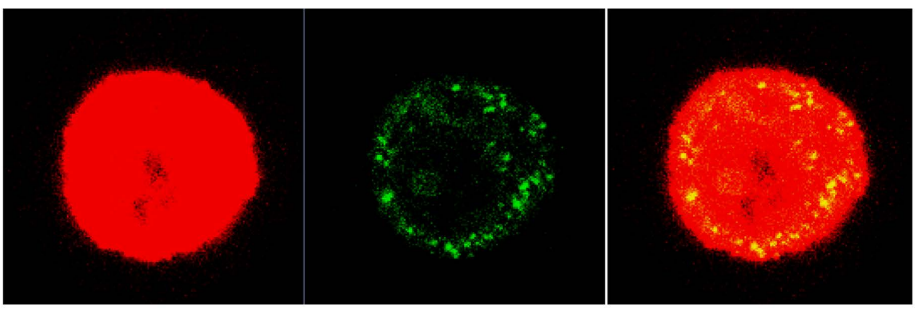

(c)

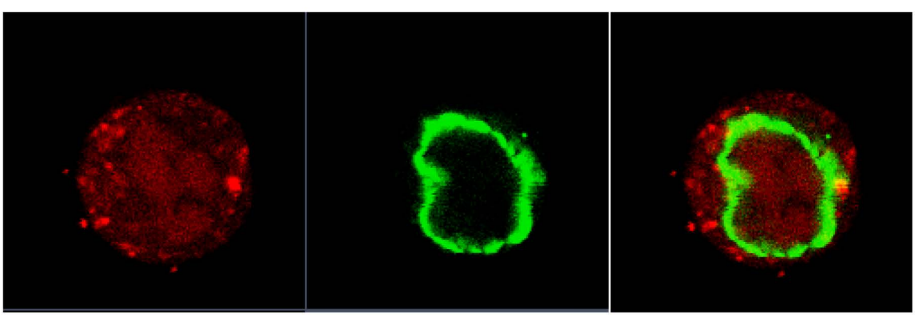

(d)

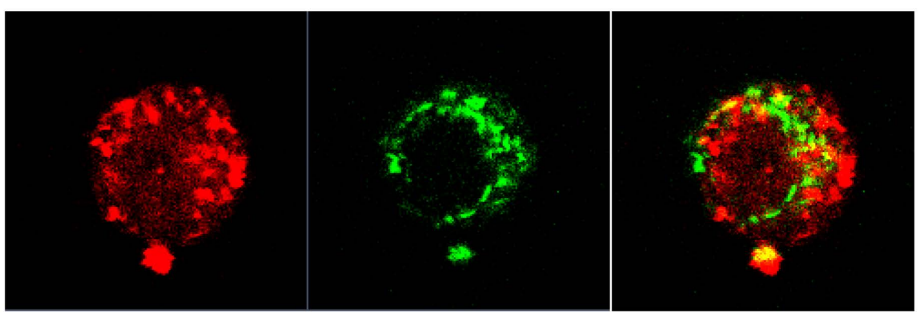

(e)

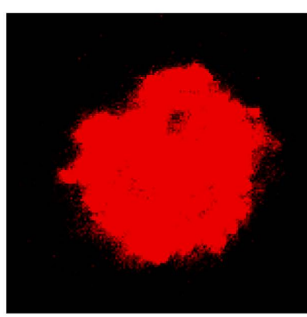

(f)

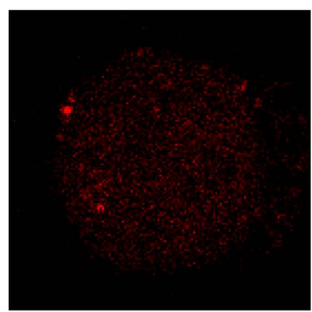

(g)

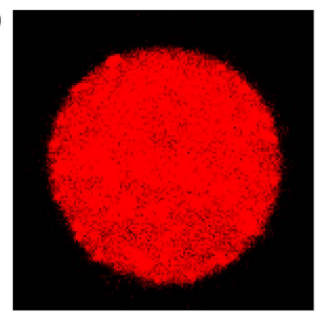

Figure 6. Representative confocal micrographs showing (a) Wild Type, (b) V144D, (c) C133W (d) C133Y (e) nontransfected (f) low Calcium (g) high intracellular calcium stained (red) ND15 cells showing GFP (Green). N = 25.

electron transport chain, catalysing the oxidation of ubiquinol and reduction of cytochrome C [15]. Here, we have shown in both quantitative protein expression (Figure 2(h)) and FACS analyses (Figure 4(c)) that cytochrome C expression was increased significantly in the TT ND15 cells containing the individual mutations. These findings thus strengthen the potential link to oxidative phosphorylation, viaubiquinol cytochrome $\mathrm{C}$, and altered energy production ultimately leading to axonal degeneration.

Further quantitative analyses were carried out which confirmed that the protein expression of RPS27a (Figure 2(f)), COTL1 (Figure 2(g)), and ORP-150 (Figure 2(i)) 


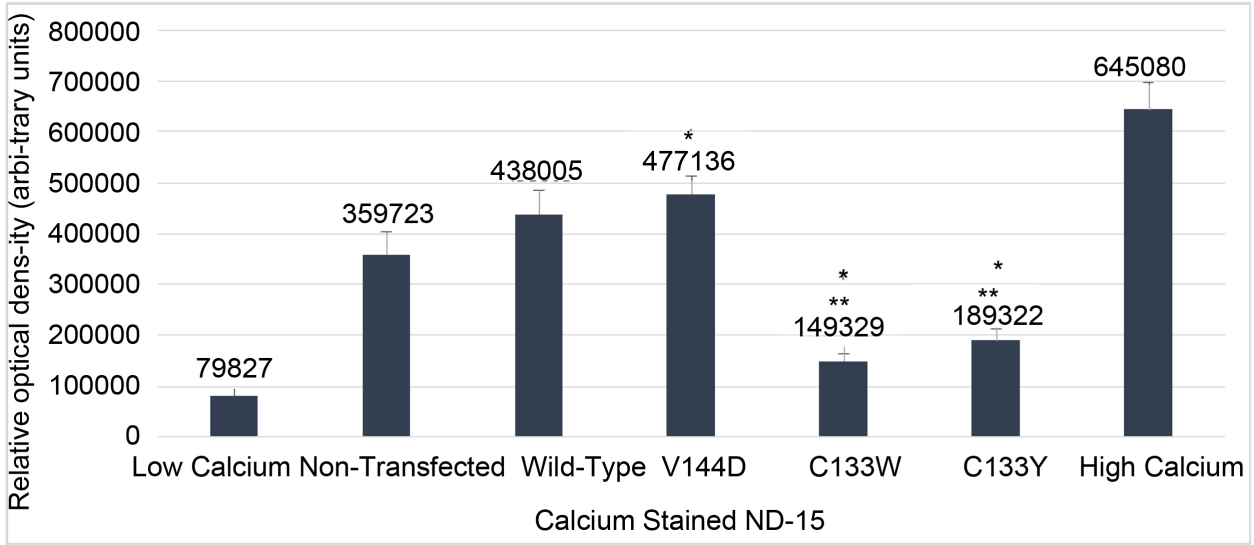

Figure 7. Relative intensity of intracellular calcium stained ND15 cells. Graph depicting relative optical density of calcium staining in NT, wild type and mutant ND15 cells $(\mathrm{n}=25) .\left({ }^{*}\right) p<0.05$, vs nontransfected; $\left(^{* *}\right) p<0.05$, vs wild-type. Errors bar depict SE of means.

Table 1. Summary of mascot protein identification.

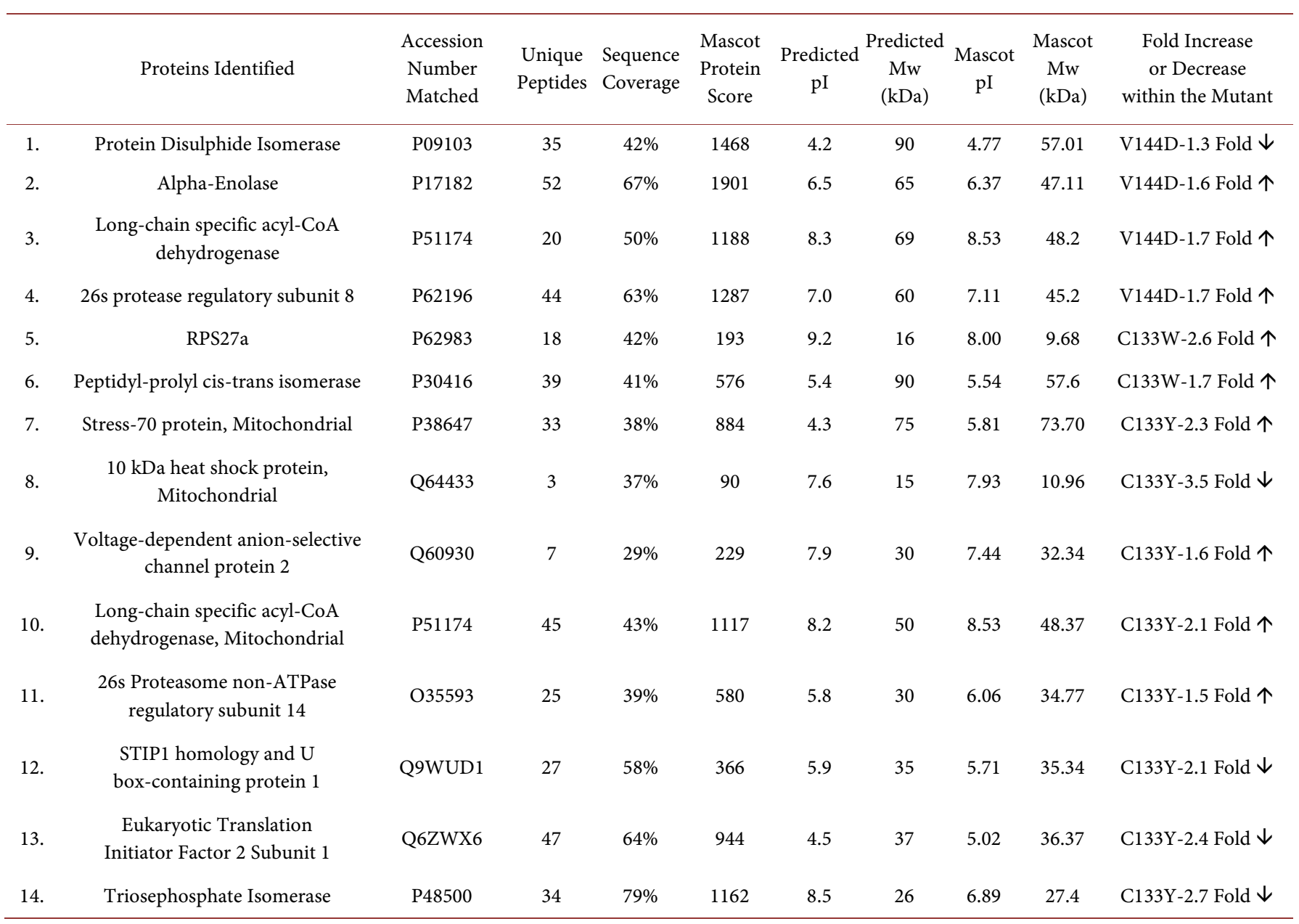

were significantly increased in the V144D TT ND15 cells. These findings correlated with results previously identified in the lymphoblast model [6] [7]. In addition, COTL1 
was significantly increased in the C133W and C133Y mutation. ORP-150 and RPS27a were found to be increased significantly in the $\mathrm{C} 133 \mathrm{Y}$ mutation; however these proteins were increased in comparison to the wild type in C133W. FACS (Figure 4) analyses confirmed the altered expression of RPS27a (Figure 4(d)), CLIC1 (Figure 4(e)), ORP-150 (Figure 4(f)), and COTL1 (Figure 4(g)) in the TT mutant cells compared to that of the wild type.

The novel findings in this study indicate links to dysfunction in oxidative phosphorylation, viaubiquinol cytochrome $\mathrm{C}$ Reductase Core Protein 1 in all three mutations causing HSN-I. The increased expression of Cytochrome $\mathrm{C}$ results in the interference of energy production and oxidative stress upon the ER, eventually causing axonal retraction, a characteristic hallmark of HSN-I. Additionally, Stress-70 mitochondrial protein levels were identified in the C133Y mutant as being increased 2.3 fold relative to the wild type (Figure 5). When mitochondria are under stress, Stress-70 protein levels increase compensating for increased oxidative damage and maintain normal protein import and synthesis [20]. Thus, if mitochondrial oxidative stress is increased (potentially via ROS production), further cellular damage would occur, ultimately leading to impaired ER efficiency eventually resulting in ER stress.

It is evident that there is an increase in oxidative and ER stress within the cells containing HSN-I mutations. This is demonstrated by the increased expression of ORP150, CLIC1, COTL1 and RPS27a. ORP-150 is an important molecular chaperone of the ER during stress [18]. CLIC1 is a redox-sensitive protein which usually exists in a soluble form in the cytoplasm but during times of stress undergoes structural changes and inserts into lipid membranes [17]. COTL1 is an actin binding partner with upregulation in response to stress upon the cytoskeletal system [19]. Taken together, these data strongly suggests that oxidative stress could be linked to increases in ubiquinol cytochrome C. Thus, an increase in ORP-150 potentially compensates and protects the cell from an increase in ROS production, causing a shift in CLIC1 expression and stabilisation of the cytoskeleton via COTL1. RPS27a is responsible for targeting misfolded proteins for destruction, with an apparent increase highlighting potential increases in misfolded proteins and protein aggregation due to oxidative stress [16].

Further strengthening the connection between ER stress and HSN-I, peptidyl-prolyl cis-trans isomerase was found to be increased in abundance by 1.7 fold in the $\mathrm{C} 133 \mathrm{~W}$ mutant. This protein ensures newly synthesised proteins are folded into their correct conformation [21]. The $26 \mathrm{~s}$ proteasome is responsible for regulating the proteome through degradation of ubiquitin-tagged substrates [22]. $26 \mathrm{~s}$ proteasome regulatory subunit 8 was found to be increased in abundance by 1.7 fold in the V144D mutation [22]. The increase in abundance of these two proteins coupled with the increased expression of RPS27a and ORP-150 highlights the possible increased oxidative stress affecting protein folding conformation.

\section{Conclusions}

Calcium is an important signaling molecule involved in the regulation of many cellular 
functions. Mitochondrial calcium uptake has been shown to lead to free radical production, with a delicate balance existing between moderate ROS production to modulate physiological signaling and overproduction of ROS which can ultimately lead to oxidative and ER stress [23] [24]. Decreases in calcium are believed to be a cellular response to increased stress, serving as a mechanism to limit further damage and increase cell survival [24]. As part of this study, we examine the intracellular levels of calcium in wild type, V144D, C133W, and C133Y. Whilst intracellular calcium is decreased within C133W and C133Y, calcium within the V144D mutation is increased. Hence, is the increased level of calcium a correlation of ER stress and mitochondrial dysfunction occurring, and the result of the V144D-mutation being unable to reduce intracellular calcium to compensate and protect the cell? Could this difference give insight into how the three mutations differ, ultimately causing HSN-I? Further investigation into intracellular and mitochondrial calcium levels is required to delineate the differences within the three mutations.

This investigation has shown a correlation between previous studies, revealing an increase in a mitochondrial electron transport chain protein, increases in proteins induced by oxidative stress and changes in the intracellular calcium levels in all three SPTLC1 mutations causing HSN-I. These findings provide further evidence for mitochondrial and ER dysfunction occurring as a result of mutations in SPTLC1. These novel findings provide critical new directions in understanding the underlying molecu-

lar and cellular alterations broadly applicable (and specific) to all mutations causing HSN-I and neurodegenerations as a whole.

\section{References}

[1] Dawkins, J.L., Hulme, D.J., Brahmbhatt, S.B., Auer-Grumbach, M. and Nicholson, G.A. (2001) Mutations in SPTLC1, Encoding Serine Palmitoyltransferase, Long Chain Base Subunit-1, Cause Hereditary Sensory Neuropathy Type I. Nature Genetics, 27, 309-312. https://doi.org/10.1038/85879

[2] Hanada, K. (2003) Serine Palmitoyltransferase: A Key Enzyme of Sphingolipid Metabolism. Biochimica et Biophysica Acta, 1632, 16-30. https://doi.org/10.1016/S1388-1981(03)00059-3

[3] Verhoeven, K., Coen, K., De Vriendt, E., Jacobs, A., Van Gerwen, V., Smouts, I., Pou-Serradell, A., Martin, J.J., Timmerman, V. and De Jonghe, P. (2004) SPTLC1 Mutation in Twin Sisters with Hereditary Sensory Neuropathy Type I. Neurology, 62, 1001-1002. https://doi.org/10.1212/01.WNL.0000115388.10828.5C

[4] Wei, J., Yerokun, Y., Liepelt, M., Momin, A., Wang, E., Hanada, K. and Merril Jr., A.H. (2007) 2-1 Serine Palmitoyltransferase. In: Hirabayashi, Y., Igarashi, Y. and Merril Jr., A.H., Eds., Sphingolipid Biology, Springer, Berlin, 25-27.

[5] Dyck, P.J. and Thomas, P.K. (2005) Dyck: Peripheral Neuropathy. 4th Edition, Mosby, Philadelphia.

[6] Stimpson, S.E., Coorssen, J.R. and Myers, S.J. (2015) Mitochondrial Protein Alterations in a Familial Peripheral Neuropathy Caused by Mutations in the Sphingolipid Protein, SPTLC1. Journal of Biological Chemistry, 8, 25-35. https://doi.org/10.1007/s12154-014-0125-X

[7] Stimpson, S.E., Coorssen, J.R. and Myers, S.J. (2016) Isolation and Identification of ER As- 
sociated Proteins with Unique Expression Changes Specific to the V144D SPTLC1 Mutations in HSN-I. Analytical Biochemistry, 5, 248.

[8] Stimpson, S.E., Coorssen, J.R. and Myers, S.J. (2015) Proteome Alterations Associated with the V144D SPTLC1 Mutation That Causes Hereditary Sensory Neuropathy-I. Electronic Journal of Biology, 11, 176-186.

[9] Churchward, M., Butt, R.H., Lang, J., Hsu, K. and Coorssen, J. (2005) Enhanced Detergent Extraction for Analysis of Membrane Proteomes by Two-Dimensional Gel Electrophoresis. Proteome Science, 3, 5. https://doi.org/10.1186/1477-5956-3-5

[10] Butt, R.H. and Coorssen, J.R. (2005) Postfractionation for Enhanced Proteomic Analyses: Routine Electrophoretic Methods Increase the Resolution of Standard 2D-PAGE. Journal of Proteome Research, 4, 982-991. https://doi.org/10.1021/pr050054d

[11] Gauci, V.J., Padula, M.P. and Coorssen, J.R. (2013) Coomassie Blue Staining for High Sensitivity Gel-Based Proteomics. Journal of Proteomics, 90, 96-106.

https://doi.org/10.1016/j.jprot.2013.01.027

[12] Wright, E.P., Partridge, M.A., Padula, M.P., Gauci, V.J., Malladi, C.S. and Coorssen, J.R. (2014) Top-Down Proteomics: Enhancing 2D Gel Electrophoresis from Tissue Processing to High-Sensitivity Protein Detection. Proteomics, 14, 872-889. https://doi.org/10.1002/pmic.201300424

[13] Myers, S., Malladi, C., Hyland, R., Bautista, T., Boadle, R., Robinson, P. and Nicholson, G. (2014) Mutantions in the SPTLC1 Protein Cause Mitochondrial Structual Abnormalisites and Endoplasmic Reticulum Stress in Lymphoblasts. DNA and Cell Biology, 33, 399-407. https://doi.org/10.1089/dna.2013.2182

[14] Jang, C.Y., Wong, J., Coppinger, J.A., Seki, A., Yates, J.R. and Fang, G. (2008) DDA3 Recruits Microtubule Depolymerase Kif2a to Spindle Poles and Controls Spindle Dynamics and Mitotic Chromosome Movement. Journal of Cell Biology, 181, 255-267. https://doi.org/10.1083/jcb.200711032

[15] Crofts, A.R. (2004) The Cytochrome Bcl Complex: Function in the Context of Structure. Annual Review of Physiology, 66, 689-733. https://doi.org/10.1146/annurev.physiol.66.032102.150251

[16] Hallengren, J., Chen, P.C. and Wilson, S.M. (2013) Neuronal Ubiquitin Homeostasis. Cell Biochemistry and Biophysics, 67, 67-73. https://doi.org/10.1007/s12013-013-9634-4

[17] Veraimo, S., Milton, R.H., Duchen, M.R. and Mazzanti, M. (2010) Chloride Intracellular Channel 1 (CLIC1): Sensor and Effector during Oxidative Stress. FEBS Letters, 584, 20762084. https://doi.org/10.1016/j.febslet.2010.02.073

[18] Behnke, J. and Hendershot, L.M. (2014) The Large Hsp70 Grp170 Binds to Unfolded Protein Substrates in Vivo with a Regulation Distinct from Conventional Hsp70s. Journal of Biological Chemistry, 289, 2899-2907. https://doi.org/10.1074/jbc.M113.507491

[19] Provost, P., Doucet, J., Stock, A., Gerisch, G., Samuelsson, B. and Radmark, O. (2001) Coactosin-Like Protein: A Human F-Actin-Binding Protein: Critical Role of Lysine-75. Biochemical Journal, 359, 255-263. https://doi.org/10.1042/bj3590255

[20] Herrmann, J.M., Stuart, R.A., Craig, E.A. and Neupert, W. (1994) Mitochondrial Heat Shock Protein 70, a Molecular Chaperone for Proteins Encoded by Mitochondrial DNA. Journal of Cell Biology, 127, 893-902. https://doi.org/10.1083/jcb.127.4.893

[21] Shaw, P.E. (2002) Peptidyl-Prolyl Isomerases: A New Twist to Transcription. EMBO Reports, 3, 521-526. https://doi.org/10.1093/embo-reports/kvf118

[22] Matyskiela, M.E., Lander, G.C. and Martin, A. (2013) Conformational Switching of the 26s Proteasome Enables Substrate Degradation. Nature Structural \& Molecular Biology, 20, 
781-788. https://doi.org/10.1038/nsmb.2616

[23] Glancy, B. and Balaban, R.S. (2012) Role of Mitochondrial $\mathrm{Ca}^{2+}$ in the Regulation of Cellular Energetics. Biochemistry, 51, 2959-2973. https://doi.org/10.1021/bi2018909

[24] Feissner, R.F., Skalska, J., Gaum, W.E. and Sheu, S.S. (2009) Crosstalk Signaling between Mitochondrial $\mathrm{Ca}^{2+}$ and Ros. Frontiers in Bioscience, 14, 1197-1218.

https://doi.org/10.2741/3303

Submit or recommend next manuscript to SCIRP and we will provide best service for you:

Accepting pre-submission inquiries through Email, Facebook, LinkedIn, Twitter, etc. A wide selection of journals (inclusive of 9 subjects, more than 200 journals)

Providing 24-hour high-quality service

User-friendly online submission system

Fair and swift peer-review system

Efficient typesetting and proofreading procedure

Display of the result of downloads and visits, as well as the number of cited articles

Maximum dissemination of your research work

Submit your manuscript at: http://papersubmission.scirp.org/

Or contactwjins@scirp.org 